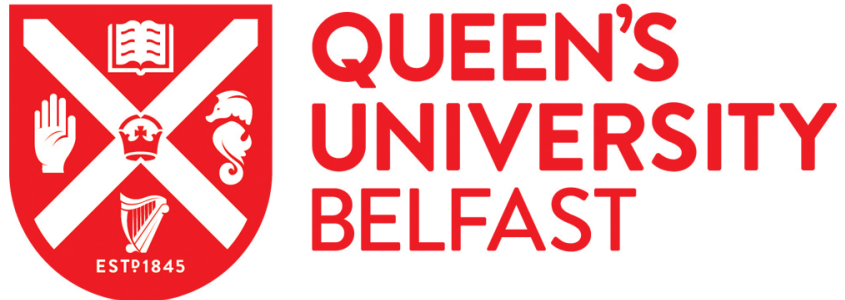

\section{Updated understanding of WRN variants using the Japanese whole- genome reference panel 3.5KJPNv2}

Fukunaga, H., Prise, K. M., \& Taki, Y. (2019). Updated understanding of WRN variants using the Japanese whole-genome reference panel 3.5KJPNv2. Geriatrics and Gerontology International, 19(9), 961-962. https://doi.org/10.1111/ggi.13724

\section{Published in:}

Geriatrics and Gerontology International

\section{Document Version:}

Peer reviewed version

Queen's University Belfast - Research Portal:

Link to publication record in Queen's University Belfast Research Portal

\section{Publisher rights}

(c) 2019 Japan Geriatrics Society. This work is made available online in accordance with the publisher's policies. Please refer to any applicable terms of use of the publisher.

\section{General rights}

Copyright for the publications made accessible via the Queen's University Belfast Research Portal is retained by the author(s) and / or other copyright owners and it is a condition of accessing these publications that users recognise and abide by the legal requirements associated with these rights.

Take down policy

The Research Portal is Queen's institutional repository that provides access to Queen's research output. Every effort has been made to ensure that content in the Research Portal does not infringe any person's rights, or applicable UK laws. If you discover content in the Research Portal that you believe breaches copyright or violates any law, please contact openaccess@qub.ac.uk. 


\section{Updated understanding of $W R N$ variants using the Japanese whole- genome reference panel 3.5KJPNv2}

Hisanori Fukunaga, ${ }^{1,2,3}$ Kevin M. Prise ${ }^{1}$ and Yasuyuki Taki ${ }^{2,3}$

${ }^{1}$ Centre for Cancer Research and Cell Biology, Queen's University Belfast, Belfast, UK

${ }^{2}$ Tohoku Medical Megabank Organization, Tohoku University, Sendai, Japan

${ }^{3}$ Department of Geriatric Medicine and Neuroimaging, Tohoku University Hospital, Sendai, Japan

\section{Correspondence:}

Hisanori Fukunaga, MD

Centre for Cancer Research and Cell Biology, Queen's University Belfast

97 Lisburn Road, Belfast BT9 7AE, UK

Tel: +44 2890972760

Fax: +44 2890972776

E-mail: hfukunaga01@qub.ac.uk

ORCID: http://orcid.org/0000-0002-6264-187X

\section{Disclosure statement}

The authors declare no conflict of interest. 


\section{Dear Editor,}

Werner syndrome (WS), an autosomal recessive disorder that causes deficiency of the WRN protein, ${ }^{1}$ presents clinical features suggestive of accelerated aging. ${ }^{2}$ This progeroid syndrome was originally described in 1904, and more than 1200 patients were reported from 1904 to 1996, with 845 from Japan. ${ }^{3}$ The WRN protein plays a role in DNA replication, transcription, repair, and recombination; thus, genetic instability has been observed in WS patients and WRN heterozygous mutation carriers. ${ }^{4}$ Recently, an international research group, including the Japanese Werner Consortium (Chiba, Japan), reported a total of 83 novel WRN mutations among WS patients, as well as 75 mutations already reported in the literature,${ }^{5}$ suggesting that the genetic diversity of $W R N$ heterozygous mutation carriers is greater than expected.

The combination of data science and biobank sample collection has the potential to clarify the frequencies of disease-related genetic variants in a given population. ${ }^{6}$ To investigate the diversity of $W R N$ gene variants, we used the $3.5 \mathrm{~K}$ Japanese wholegenome reference panel "3.5KJPNv2," allele frequencies from 3,552 individuals, which is a part of the Japanese Multi Omics Reference Panel (jMorp, available at https://jmorp.megabank.tohoku.ac.jp/201806/) released from Tohoku University’s Tohoku Medical Megabank Organization (ToMMo). ${ }^{7}$ The two large-scale prospective studies of ToMMo, Tohoku Medical Megabank Project Community-Based Cohort Study (TMM CommCohort Study) and Tohoku Medical Megabank Project Birth and Three-Generation Cohort Study (TMM BirThree Cohort Study), were performed in Miyagi and Iwate Prefectures in Japan after the 2011 Great East Japan Earthquake and Tsunami. ${ }^{8}$ As of 2018, these projects have collected biospecimens, such as blood and urine, from more than 150,000 Japanese participants who have given informed consent. 
As shown in Figure 1, we confirmed a total of 4,632 allele variants in the WRN gene, including 1,133 (24\%) novel variants that have not yet been assigned reference SNP ID numbers (RefSNP). Furthermore, we found 12 novel missense variants in the $W R N$ gene that could change the expression and function of the WRN protein. Next, we investigated the 10 pathogenic variants in the $W R N$ gene reported by the ClinVar archive (available at https://www.ncbi.nlm.nih.gov/clinvar/): rs267607008(A>G), rs775802030(A>G), rs17847577(C>T), rs121908448(A>T), rs281865157(A>G), rs113993961(G>C), rs281865159(A>C), rs121908447(C>T), rs369158322(A>T), and rs121908446(C>T). We found one DNA sample with heterogenous mutation rs $17847577(\mathrm{C}>\mathrm{T})(0.0001), 15$ samples with heterogenous mutation rs113993961(G>C) (0.0021), and one sample with heterogenous mutation rs121908446(C>T) $(0.0001)$. Our data analysis of the whole-genome reference panel, 3.5KJPNv2, demonstrates that, with the assumption of the Hardy-Weinberg equilibrium, a large number of healthy individuals have "likely pathogenic" or "pathogenic" heterogenous variants in the WRN gene, indicating that the genetic diversity of WS patients and WRN heterozygotes is greater than previously reported ${ }^{5}$.

The combination of data science and biobank collections will lead to a better understanding of the genetic basis of Werner syndrome. Population-based wholegenome reference panels, including 3.5KJPNv2, have the great potential for future innovations in the research fields of geriatric medicine and gerontology. 


\section{References}

1. Yu CE, Oshima J, Fu YH, et al. Positional cloning of the Werner's syndrome gene. Science. 1996;272:258-262.

2. Oshima J, Sidorova JM, Monnat RJ. Werner syndrome: Clinical features, pathogenesis and potential therapeutic interventions. Ageing Res Rev. 2017;33:105-114.

3. Satoh M, Imai M, Sugimoto M, Goto M, Furuichi Y. Prevalence of Werner's syndrome heterozygotes in Japan. Lancet. 1999;353(9166):1766.

4. Moser MJ, Bigbee LW, Grant SG, et al. Genetic instability and hematologic disease risk in Werner syndrome patients and heterozygotes. Cancer Res. 2000;60:2492-2496.

5. Yokote K, Chanprasert S, Lee L, et al. WRN Mutation Update: Mutation Spectrum, Patient Registries, and Translational Prospects. Hum Mutat. 2017;38:7-15.

6. Fukunaga H, Yokoya A, Taki Y, Butterworth KT, Prise KM. Precision Radiotherapy and Radiation Risk Assessment: How Do We Overcome Radiogenomic Diversity? Tohoku J Exp Med. 2019;247:223-235.

7. Tadaka S, Saigusa D, Motoike IN, et al. jMorp: Japanese Multi Omics Reference Panel. Nucleic Acids Res. 2018;46:D551-D557.

8. Kuriyama S, Yaegashi N, Nagami F, et al. The Tohoku Medical Megabank Project: Design and Mission. J Epidemiol. 2016;26:493-511. 


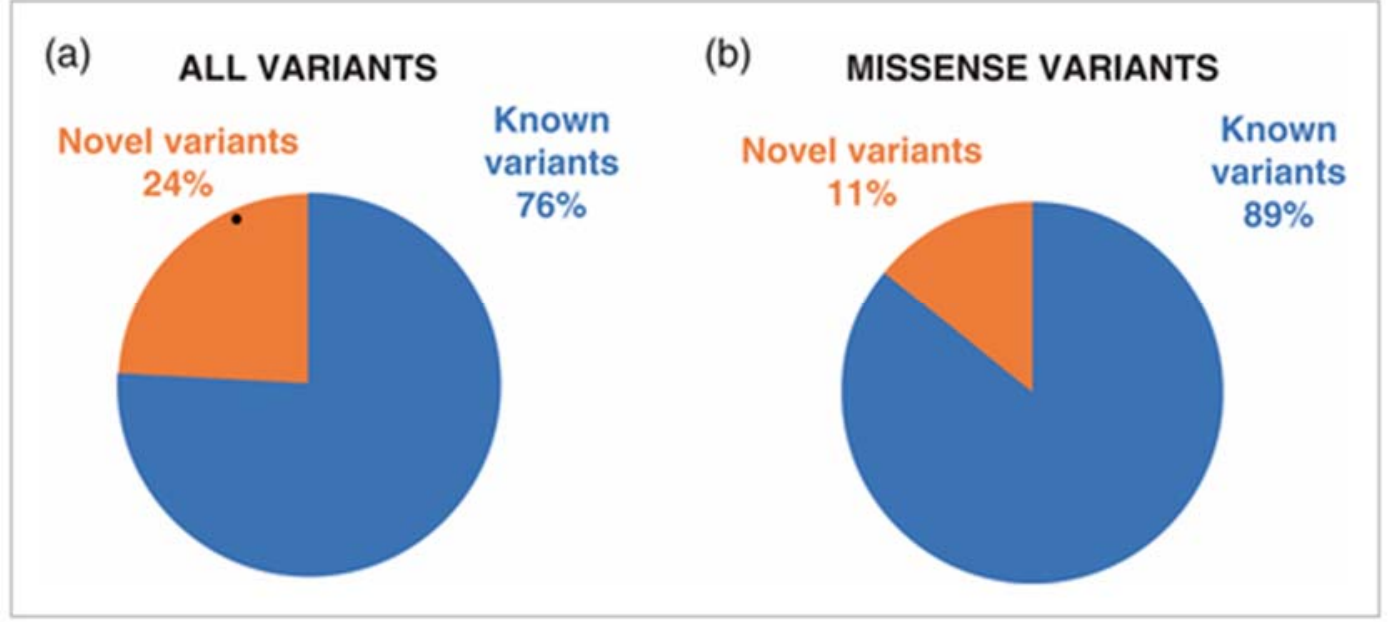

Figure 1. Variants in the WRN gene.

(a) 4,632 allele variants in the WRN gene have been confirmed, including 1,133 (24\%) novel variants that have not yet been assigned reference SNP ID numbers (RefSNP). (b) 108 missense $W R N$ variants that could change the expression or function of the WRN protein have also been confirmed, including 12 (11\%) novel variants. 